User Interface Design and Development for the Enhanced Radiological Nuclear Inspection and Evaluation (ERNIE) Tool Internship Report

B. G. Dueno Ortiz, T. W. Jacomb-Hood, S. E. Labov, K. Nelson

August 5, 2013 
This document was prepared as an account of work sponsored by an agency of the United States government. Neither the United States government nor Lawrence Livermore National Security, LLC, nor any of their employees makes any warranty, expressed or implied, or assumes any legal liability or responsibility for the accuracy, completeness, or usefulness of any information, apparatus, product, or process disclosed, or represents that its use would not infringe privately owned rights. Reference herein to any specific commercial product, process, or service by trade name, trademark, manufacturer, or otherwise does not necessarily constitute or imply its endorsement, recommendation, or favoring by the United States government or Lawrence Livermore National Security, LLC. The views and opinions of authors expressed herein do not necessarily state or reflect those of the United States government or Lawrence Livermore National Security, LLC, and shall not be used for advertising or product endorsement purposes.

This work performed under the auspices of the U.S. Department of Energy by Lawrence Livermore National Laboratory under Contract DE-AC52-07NA27344. 


\title{
User Interface Design and Development for the Enhanced Radiological Nuclear Inspection and Evaluation (ERNIE) Tool \\ Internship Report
}

\author{
Bruno G. Dueno Ortiz \\ DHS HS-STEM Summer Internship \\ Polytechnic University of Puerto Rico \\ Lawrence Livermore National Laboratory \\ Livermore, CA
}

August $9^{\text {th }}, 2013$

Prepared in fulfillment of the requirements of the Department of Homeland Security HS-Stem program and the Department of Energy's Science Graduate Laboratory Internship under the direction of S. Labov and K. Nelson in the Global Security Division at Lawrence Livermore National Laboratory. 


\section{TABLE OF CONTENTS}

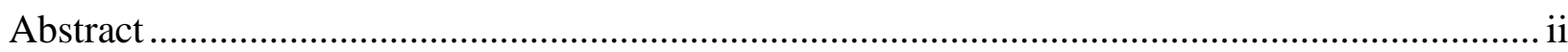

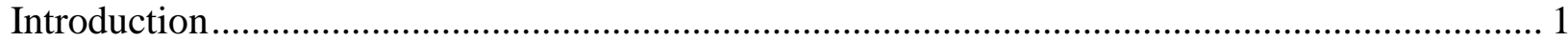

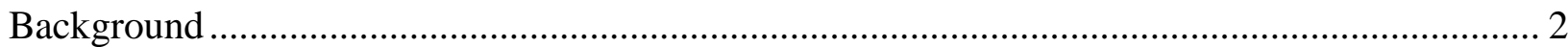

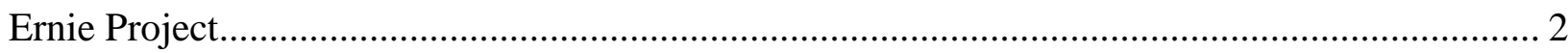

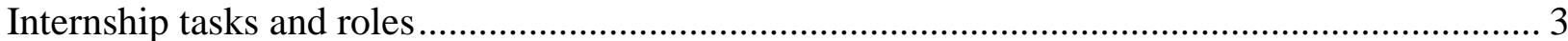

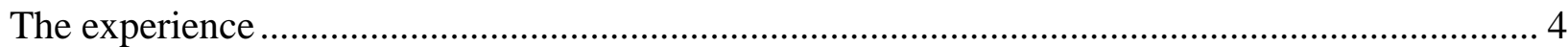

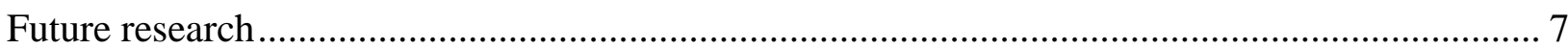

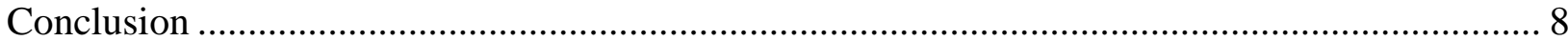

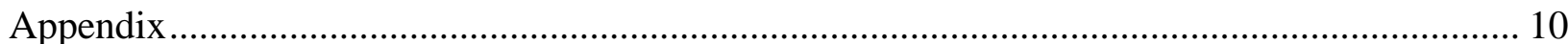




\begin{abstract}
There are radioactive and nuclear threats that affect the security of the United States. The Enhanced Radiological Nuclear Inspection Evaluation project aims to develop better methods for finding these threats. The general user interface of ERNIE needs to efficiently and clearly display all the necessary information that is used to support the decision of the Customs and Border Patrol officers. The Vehicle Presence Sensors (VPS) are located in various entry points all around the nation to detect any nuclear or radiological threat. The main purpose of my job in the internship is to transform MATLAB code to Java, and to create and develop a general user interface (GUI) for ERNIE using Java as the main programming language. All the tasks will be performed in the Lawrence Livermore National Laboratory in Livermore, California.
\end{abstract}




\section{INTRODUCTION}

The Enhanced Radiological Nuclear Inspection and Evaluation (ERNIE) tool has the purpose of working as a decision support system for the Vehicle Presence Sensors installed in various ports of entry in the United States. The team that I am working in the Lawrence Livermore National Laboratory has the task of creating plots and machine learning techniques to detect radiation and nuclear threats in cargo shipments. I have knowledge in information systems, decision support systems and programming, creating a good multidisciplinary mixture to benefit the team. My mentor for the graduate summer internship was Simon Labov. I also had Karl Nelson as my project leader and Jessica Rath as my administrative assistant. There was also another intern working with me but with a major in nuclear engineering called Timothy JacombHood. I had many tasks to do in the summer but most of them were using MATLAB, Python and NetBeans as the main software environments to fulfill my tasks. This experience has been one of the critical pieces of my career to be a better scientist and focus my knowledge in making advancements that can help solve the issues of the future. My career has received a push to understanding what the necessities are, and how to solve problems before they occur. I got to know more environments or special areas in which my knowledge can help for future projects. One of the benefits of this opportunity was that I can now have a better overview of what path to take in my professional future. The Department of Homeland Security has given me an opportunity like no other were I, as a minority from Puerto Rico, gained experience, knowledge, focus and determination to drive my professional career into what companies are requiring for their staff. LLNL has offered me with many lectures; seminars and tours that enhance my internship experience while giving me options to look in different research that help me in my search for a thesis research for my master's degree. The experience was not only professional, but personal to make me go above the competition in looking for a job in the future. 


\section{BACKGROUND}

The Department of Homeland Security (DHS) and other federal agencies are implementing detectors or portal monitors in points of entry around the nation to detect nuclear and radiological alarms. These alarms can become threats depending on the type of radiological or nuclear emitting container. The sensors that are being implemented are Vehicle Presence Sensors (VPS) are plastic polls in the entrance and exit of locations that receive shipments. They are being used in the ports at the moment but the detectors are not using efficient software for the analysis, demonstration and making decision more effective minimizing the margin of error. The sensors emit an alarm every time there is possibility of a threat in one of the sensors. The situation at the moment is that there are many alarms that occur daily and most of them are falsepositives. Each time there is an alarm, a team has to mobilize into the portal monitors to check the cargo and decide if the threat is real. That means that bigger funds are necessary for each port to be able to have the teams in hold for any situation that occurs while the port is working. Because our government is looking at effective ways to protect our nation, we need to look for ways that can create the highest level of protection while minimizing the long term costs. That is why the Lawrence Livermore National Laboratory has accepted a project to look for ways to make the best use of the VPS and create a better decision support interface for the team that looks for security threats in the points of entry.

\section{ERNIE PROJECT}

The Enhanced Radiological Nuclear Inspection and Evaluation (ERNIE) is a project to create decision support system that can be used to notify officers of threats that are real and with the least margin of error. The margin of error is going to be minimized by implementing machine learning techniques that can be merged into a software application that can be made into an 
application for all the points of entry. The project has also other helpers to make the best possible result. Some of the other agencies and organizations working in the project are the Carnegie Mellon University, the Pacific Northwest National Laboratory and the U.S Department of Transportation.

\section{INTERNSHIP TASKS AND ROLES}

I was part of the physical and life sciences department in the nuclear program. One of my roles as a computer science student is to be able to create plots and use a sample of the information to make a better analysis for the radiological and nuclear threat detection. Another one of my tasks is to design and develop an efficient general user interface that can be used in points of entry to show a decision support that is easy to understand for everyone working with the VPS. The application must be similar to the main applications used for security but with an easy use interface that can be adaptable and effective in giving a clear idea of what type of threats can be found entering our ports. Another one of my roles is to understand and analyze ways of making codes be more efficient or look for issues that can be address before they happen. Most of our work is done fundamentally in using the MATLAB application. This is an application that can make many things in the minimum amount of time but effectively. This is a plus in doing our research but, MATLAB is software that consumes a lot of resources and is not something portable that can be installed easily in all the computers that are connected to the portal monitors in the points of entry. Some of the options that were suggested by the group were converting everything to a more programming language that can be easy to install in many computers. The programming language had to be adaptable, efficient, portable and with all the components necessary to make a complex application with the least errors possible. Java was the selected language to use because of the combination of features that it possesses. I had also the 
task of beginning to convert the MATLAB codes into Java to be able to implement them in the application created and that it can work properly for our demo.

I have been able to create a general user interface that was approved by the team with at least 12 different revisions to address the different concerns of the agencies. I also achieved in converting some of the code necessary to keep moving the codes form MATLAB into Java. Another achievement is that I helped in using my knowledge in decision support systems to create something that is going to be effective in the daily use but easy to understand and use for the different people using it. We made as a team weekly presentation to see how the agencies think about our achievements and we know that there is a good result that is being created to nuclear and radiological threat detection. I made contributions to my research project by helping with my knowledge in understanding and creating a software application that can be later adapted to many agencies that need a guide for decision support systems.

\section{THE EXPERIENCE}

I have learned many things with my internship experience at Lawrence Livermore National Laboratory. I learned about nuclear threats and radiological threats. This can help me understand how to create better applications for detection in the future. I also learned about machine learning and all the benefits that it can provide for research in computer science. The learning code in programming was really high because in universities they try to teach you how to code, but when you go to a research or professional environment, everything can change and the challenges you had in school are now for times more critical and sensitive to changes. I knew Java but this experience has open my mind to all the libraries and options I can create and manipulate to make programs interact in specific environments and how they can be manipulated using the same tools you had from the beginning. I learned how necessary is to understand the 
people you are doing the project for, so that you can create something that they can understand and not something that you understand but they get lost every time they do something. A program needs to be easy use but precise in making users take the best decision according to facts that can be shown in the application. I have become a better team worker in my specific field of computer science. As usual, most computer scientists work alone because of making things with their own processes to make things happen. I liked that everyone in my team was working in teams and that we helped each other in creating something that should comply with all the requirements and necessities of the sponsors of the project. I also gained in my internship a better understanding of how critical thinking needs to be addressed and how to look for answers that no one considered before. I also have gain knowledge in the physics environment by using many equations and function that can be used for location analysis and presence devices. Now, I am appreciating more all the science fields and how to solve the many problems that with the best skills for each area. I have also gained a lot of vocabulary in English that can help me communicate clearly and with the right ideas for the message that I am trying to send. The indirect knowledge I have gained is in understanding scientific literature and having a better idea of how nuclear topics must be addressed and used in our benefit. My work was not only in teams but independently by making my tasks and then taking them to the teams for analysis and response.

My internship experience will greatly transform my academic career. I now want to continue my studies and make a $\mathrm{PhD}$ that can merge my knowledge in computer security, network security and information security. For me, this is a big step that I did not know the importance it had and how I could benefit from it. I want to try to merge my thesis project with creating a better computer security for nuclear information management. Because of my 
internship, I am now brainstorming many ideas that have to do with merging nuclear security with information systems and computer science. One of the main aspects that the internship changed is that I now want to look for nuclear related fields that need to beneficiate from a staff member that has knowledge in the field that I am learning at the moment. I really want to finish my master's degree in Computer Science and begin to work to be able to gain more knowledge and get the necessary skills to get a $\mathrm{PhD}$ in my areas of interest. I am planning to look for a career in fields that are more constant in tasks and not many changing projects that need to be performed. I really liked the way the lab continues the way of making many projects to be able to have enough funds. I am not used to that type of work schedule and for my future career I would like to have more focused roles that can be manipulated for one environment only. The research experience is different from a professional experience in a private entity. They can both have the same purpose of fulfilling tasks but it is different how they can manage their business. I think both layouts are really interesting and effective for someone as multidisciplinary as me.

I have taken many lectures, seminars and tours inside the lab that give a benefit to my knowledge. The DHS group was able to participate in some lectures to help us in understanding the main focuses for the present and future of the LLNL. We learned about energy, exergy and the carbon cycle. We explored the natural and anthropogenic energy and carbon cycles from the global scale down to individual sectors the economy. Another talk provided us with detailed consequences for community preparedness activities, including block-by-block analysis of observable effects, potential casualties, infrastructure effects, and response issues. Also another lecture was to develop visualization aids to understand a nuclear detonation event. We also participated of a lecture about Fukushima and the work of NARAC in solving and dealing with nuclear threats. I also participated in meeting with the Director of LLNL, the director of Global 
Security and some of the most interesting project directors in LLNL and Sandia National Laboratories. This experiences have been incredible and also a one in a lifetime moment that may never be repeated. I also participated in different tour around the facilities of the lab.

I participated in many tours the lab offers to increase the knowledge of the projects around the lab. My first tour in the summer was to the Center for Accelerator Mass Spectrometry (CAMS). They perform more than 25,000 accelerator mass spectrometry (AMS) measurements per year to identify the isotopic composition of substances. It is the world's most versatile and productive AMS facility in the world at the moment. I also participated in a tour for the Terascale Facility. The facility has some of the fastest supercomputers of the world. There are various types of supercomputers differing from parallel computing to variations in computer architecture. Another tour was the National Ignition Facility (NIF) which has the world's largest laser. It focuses the intense energy of 192 giant laser beams on a BB-sized target filled with hydrogen fuel fusing, or igniting, the hydrogen atoms. This is the same fusion energy process that makes the stars shine and provides the life-giving energy of the sun. The last tour I participated was the Target Facility for NIF. It is the place where NIF creates and separates the components and creates the target used in the laser shots.

\section{FUTURE RESEARCH}

The Department of Homeland Security of the United States needs to keep putting effort in cyber-security and information security. Many organizations are outsourcing there IT departments to minimize the spending and lower the budgets. That may be the best option in short term but it is not a logical decision in the long run because of the changes that are happening. Increasing research in protecting information should be separated from programs for computer security. I think that DHS should work more with private companies to increase the 
environment and behavior of data or information. Also the research in network security should be put in one of the critical areas of interest for DHS. They should give more opportunity to minorities to try to work for them in a coop to leave special students with more options of serving the nation using the best abilities of each one.

\section{CONCLUSION}

In conclusion for my report I can say that this was an experience that changed my life in many ways. The increase in knowledge for my professional career has been really big giving me options and areas of interest that I did not know. I made a Java interface for the ERNIE project that will continue being in development until 2014. The application is going to keep running for each scan until it finds a threat. If there is an alarm that ERNIE detects, it will show all the necessary information to make the employee make the best decision possible according to all the information that the GUI showed him. The user interface shows plots that are generated by receiving and analyzing the information from the vehicle presence sensors. I did not work in the machine learning process directly, but I saw how CMU and others helped in doing the machine learning to make a better discrimination of what really an alarm is. I also was able to create a clean sample of information to be able to create clusters. Some of the clusters that can be made with the sample are vehicle clusters, plot clusters and threat clusters. Every point of entry can have different threats, but with machine learning the threats can be normalized to have a better analysis.

The best programs are written so that computing machines can perform the tasks quickly and everyone can understand them clearly. The best comparison of a programmer is that he is like an essayist who works with traditional aesthetic and literary forms as well as mathematical concepts, to communicate the form that an algorithm works and to give enough evidence to a the 
user to make a correct decision. The missions and goals of DHS should keep going with a better focus in computer, network and information security. I learned a lot from this experience and hope that it will repeat in the future but for a more permanent job position and keep helping other with my specific set of skills. I want to thank my mentor Simon Labov for all the help in training us and giving us support to perform our tasks in accordance with what sponsors are looking for. I also want to thank Karl Nelson for all his help as a leader in answering all our questions and be there for every tasks we were not sure how to make. Barry Goldman was the DHS advisor and help in many ways to have the best experience in learning and making us be a good asset to our projects. Last but not least, I want to thank Jessica Rath for being the best administrative assistant solving all our situation making sure our work environment is prepared for all our needs to complete the tasks. Everyone in the lab helped us so much that I cannot express how happy I am to accomplish the opportunity of being part of the Lawrence Livermore National Laboratory. 


\section{APPENDIX}
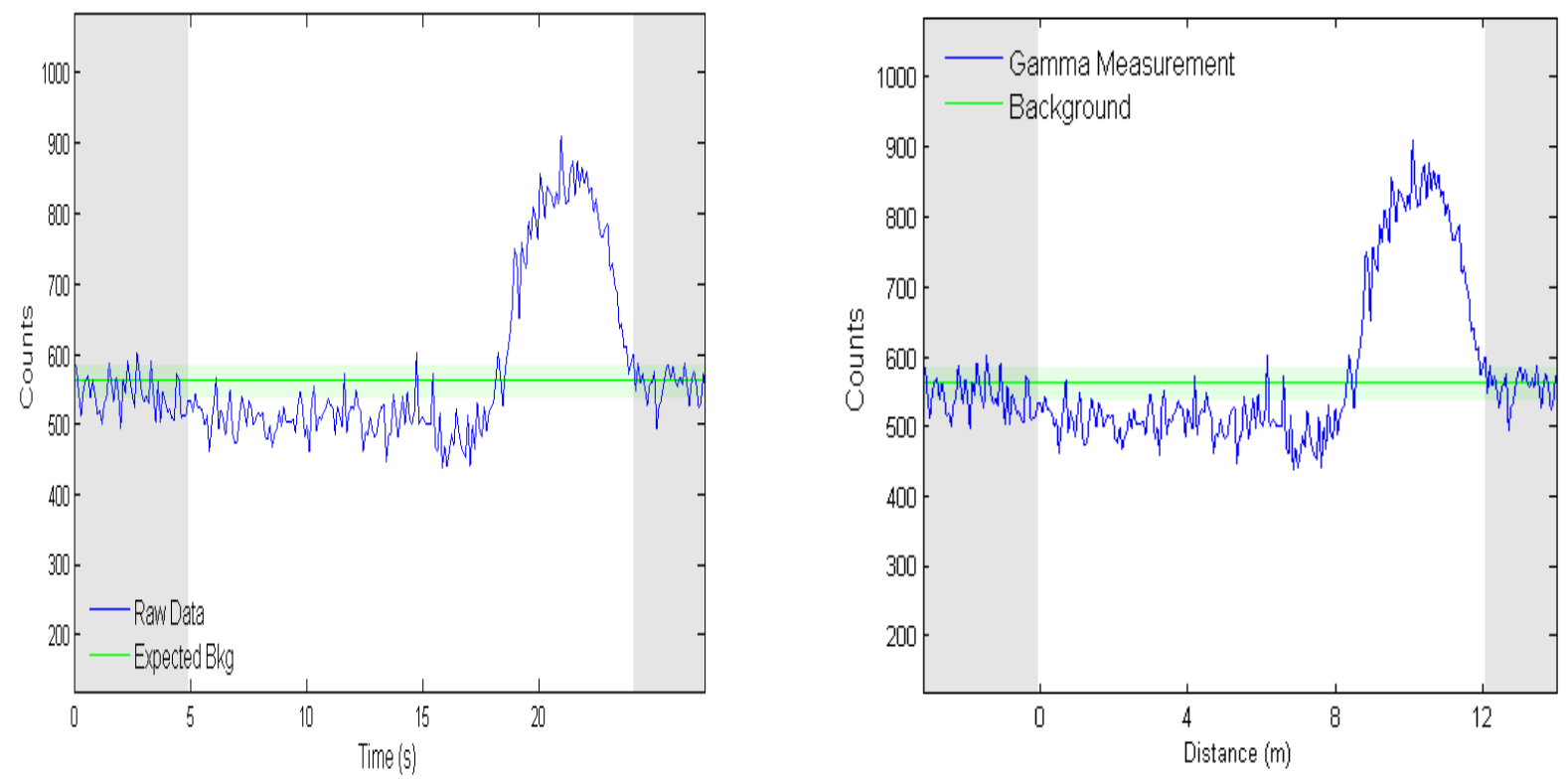

Figure 1: Gamma Scans in time and distance space
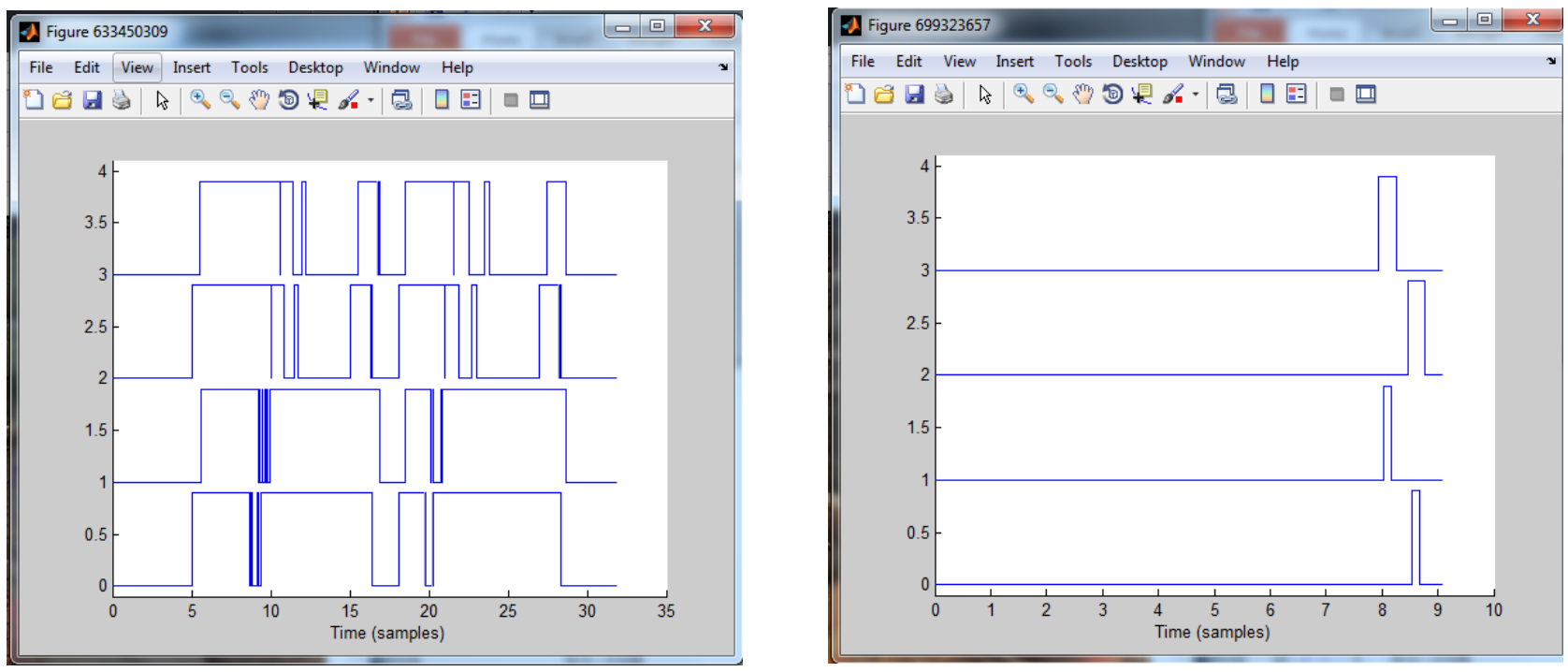

Figure 2: Caption Goes Here 
Typical portal monitors

have 4 plastic detectors

with vehicle presence

sensors (VPS)

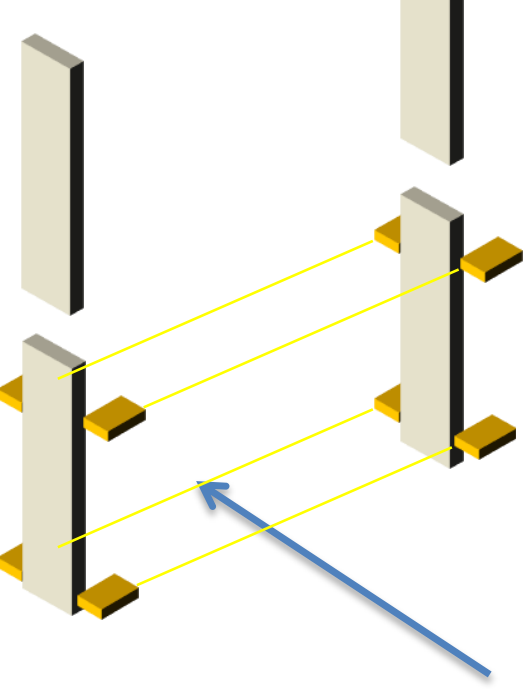

Figure 3: Vehicle Presence Sensors

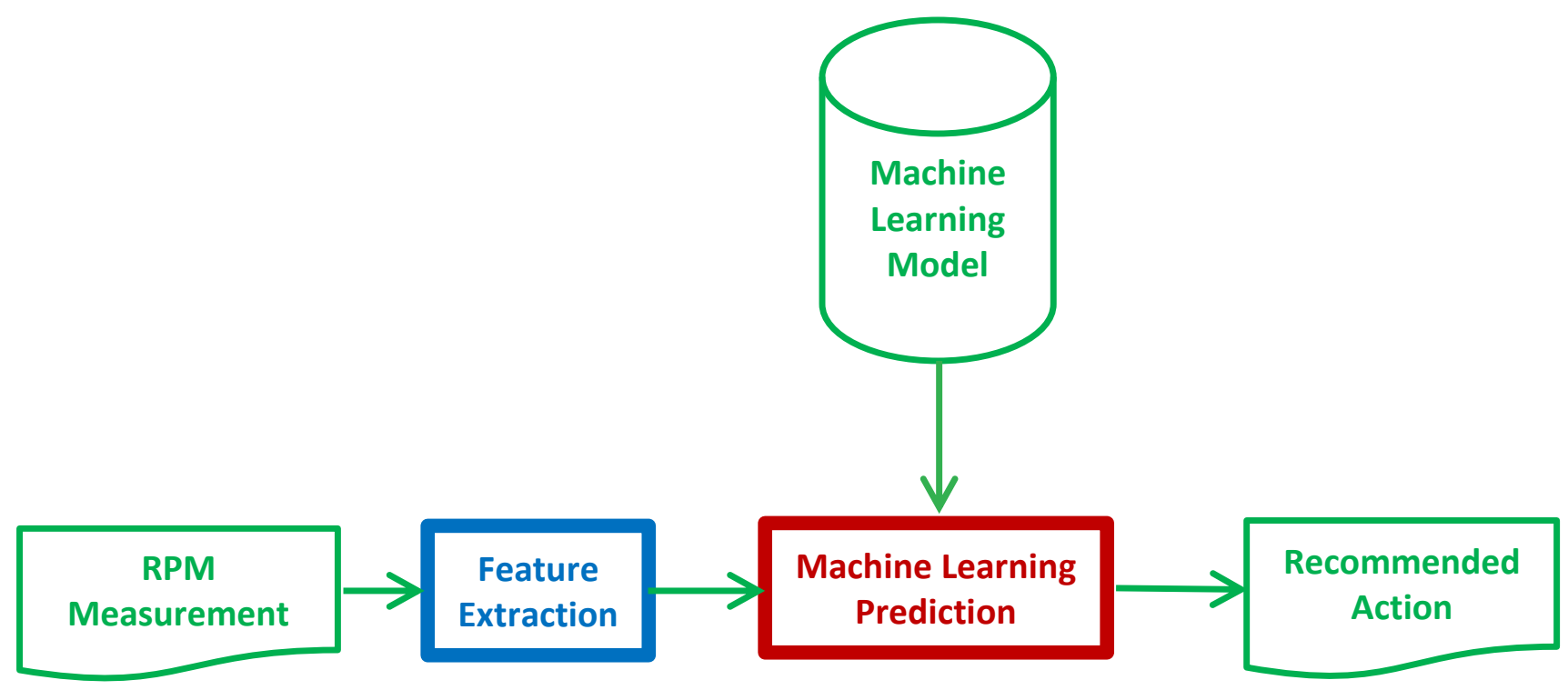

Figure 4: Basic Project Development 


\begin{tabular}{|c|c|}
\hline \multicolumn{2}{|c|}{$\begin{array}{l}\text { RPM } 8 \text { Alarm } \\
\text { (Ground Truth) }\end{array}$} \\
\hline Vehicle ID & Action \\
\hline 622122632 & (2) 汧 \\
\hline 622122631 & (2) \\
\hline 622122630 & (2) 田 \\
\hline 622122629 & (2) \\
\hline 622122628 & $\rightarrow$ 후 \\
\hline 622122627 & $\rightarrow$ 돌 \\
\hline 622122626 & (2) $\%$ \\
\hline & \\
\hline
\end{tabular}

RPM8 Alarm

Gamma

Gross

Ratio 1

Ratio 2

Ratio 3

Ratio 4

Neutron

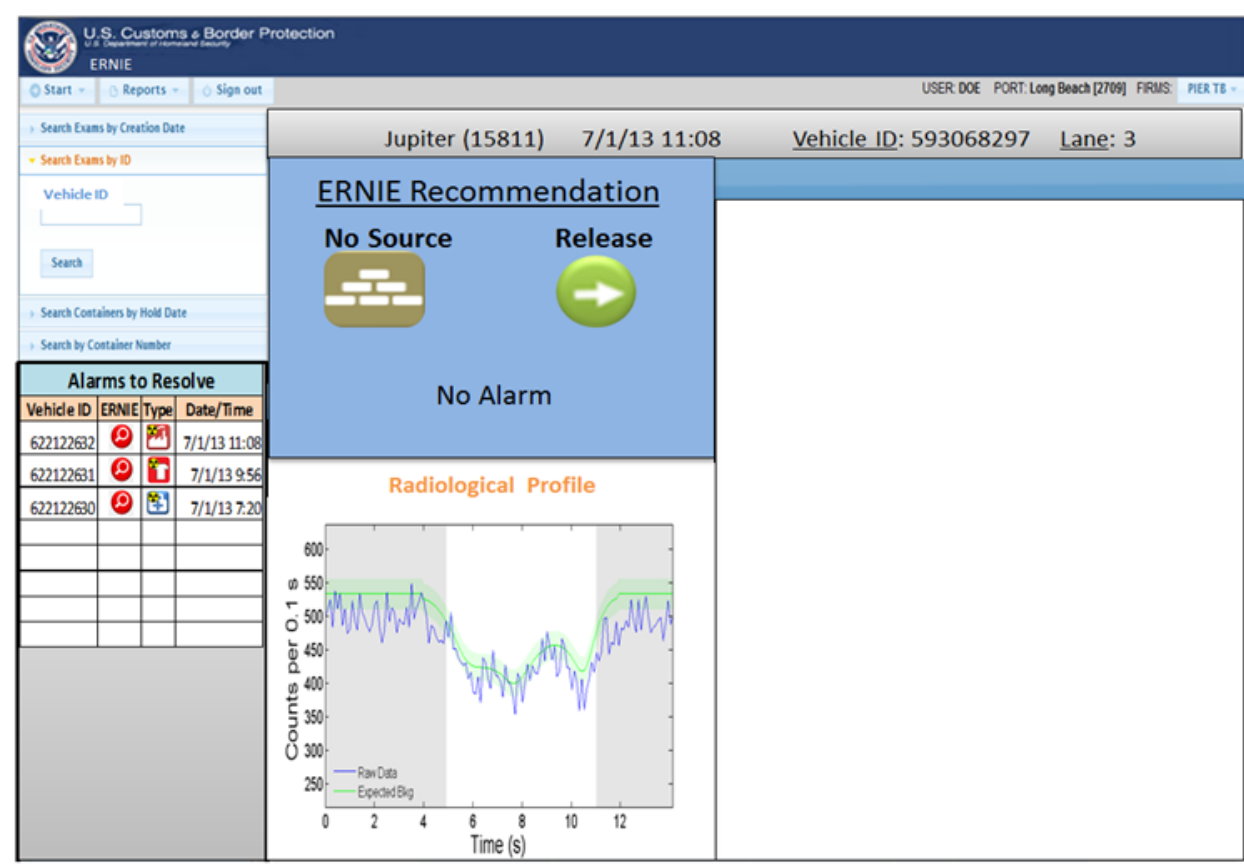

Figure 5: Demo Application with no alarms 


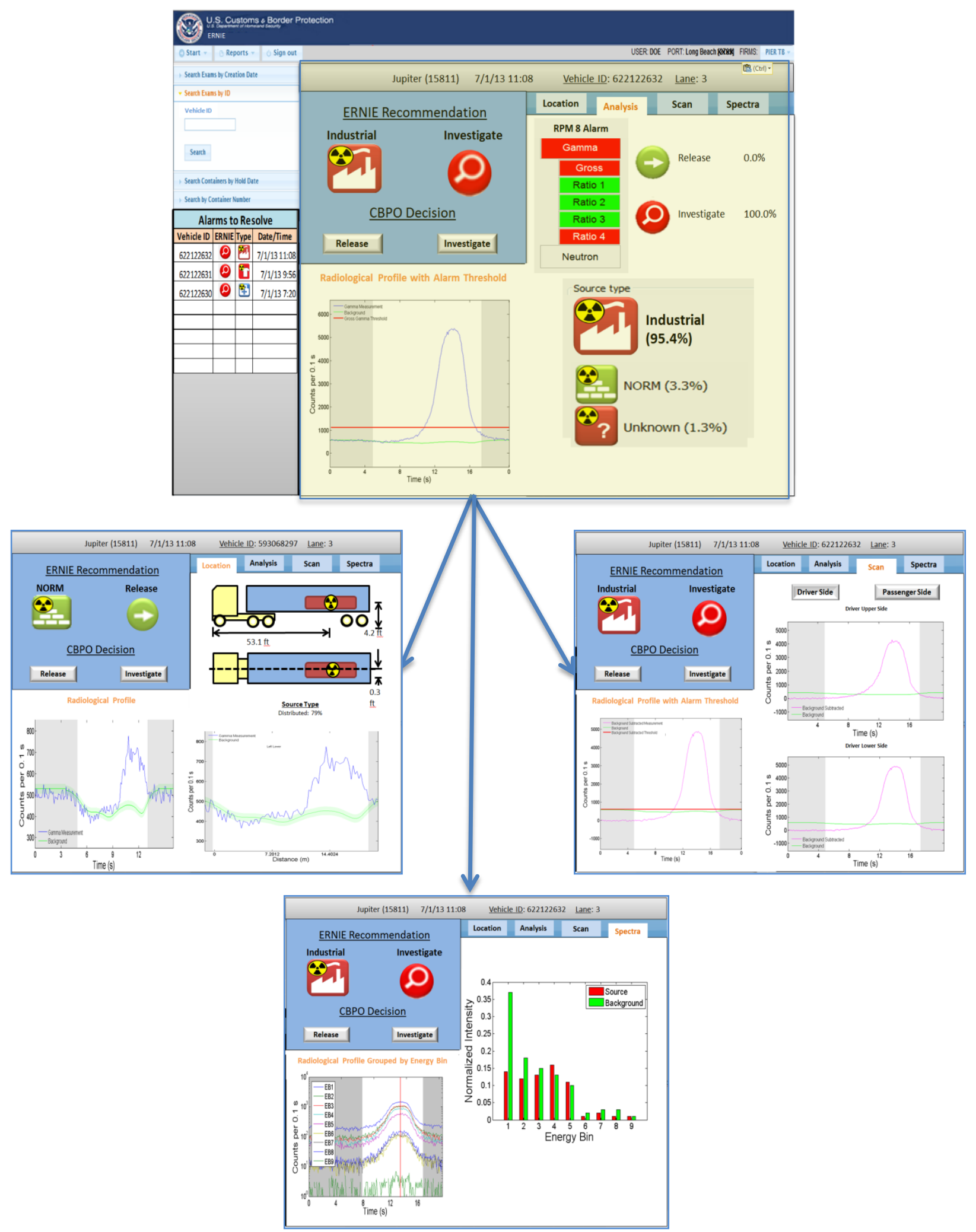

Figure 6: Ernie Alarming screens 